https://doi.org/10.31470/2706-7904-2021-16-249-253

\title{
ДИСКУРСИВНЫЕ СРЕДСТВА ВЫРАЖЕНИЯ ЭМОЦИОНАЛЬНОГО ОТНОШЕНИЯ В ИНТЕРНЕТ-ДИСКУРСЕ (НА ПРИМЕРЕ ФРАНЦУЗСКОГО ЯЗЫКА)
}

\section{Discursive Means of Expressing Emotional Attitude in Internet Discourse (on the Example of the French Language)}

\author{
Antonina Rafikova \\ Ph.D. in Psychology, Senior Researcher \\ State Academic University for the Humanities (Russia) \\ antoninaraf@yanndex.ru \\ https://orcid.org/0000-0001-9831-6027
}

\begin{abstract}
The article reveal the problem of discursive means of expressing emotional attitude in Internet discourse on the example of the French language. A theoretical review of research made it possible to identify the main lexical means of expressing emotional state in internet communication in French versions of Facebook and Twitter. The role of interjections and hashtags in the expression of emotional attitudes in Internet discourse is described. The lexical and rhetorical features of the hate speech are considered. The conclusions are presented.
\end{abstract}

Key words: internet discourse, emotions, discursive means, hate speech.

\section{Вступление \\ Introduction}

В современном обществе интернет играет доминирующую роль во многих сферах человеческой деятельности. Дискурсивная реальность интернета представляет собой феномен, конституируемый активностью и переживаниями интернетпользователей (Павлова, Гребенщикова \& Кубрак, 2020). Основными характеристиками дискурсивной реальности интернета являются: (1) вариативность дискурсивного отображения событий, задающего способы говорения о мире и трансформирующего его картину; (2) коммуникативная контекстность, связанная с принятыми нормами, намерениями, речевыми интенциями говорящих и другими факторами; (3) интерактивность и мультимодальность, повышающие оказываемое эмоциональное воздействие и доверие к получаемой информации (там же). 
Функцию воздействия реализует любое высказывание, не только политический или рекламный дискурс, но и обыденное, нейтральное высказывание предполагает психологическое воздействие. Оно может реализоваться с помощью введения информации в оценочно окрашенный контекст, использования намека, метафоры (Баранов, 2007). Например, метафора пути незаметно для адресата задает вектор осмысления событий, побуждая видеть мир как движение по дороге («свернуть с пути») (Павлова, 2013). В целом выделяют лексические и синтаксические, формально-структурные и семантические, вербальные и невербальные, простые и комплексные приемы воздействия. Для оказания воздействия используются различные приемы: употребление эмоционально окрашенных слов, использование эвфемизмов, замена активных конструкций пассивными, позволяющая, не упоминая о действующих лицах, снять вопрос об ответственности (Павлова, 2013). С другой стороны, можно говорить о риторических стратегиях и реализующих их приемах и тактиках. Например, формирование оппозиции «свои» - «другие» имеет ключевое значение и для дискредитации противника и для создания «своего круга», и для мобилизации общественного мнения и, кроме того, может применяться в русле стратегии изменения оценок (Павлова, 2013).

\section{Методы и методики исследования Methods and Techniques of the Research}

В статье представлен обзор работ, посвященных исследованию выражению эмоционального отношения и оказанию эмоционального воздействия с помощью дискурсивных средств в социальных сетях Twitter и Facebook франкоязычного сегмента интернета (Elouni, 2018; Monnier, Seoane \& Gardenier, 2020).

\section{Результаты \\ Results}

В первую очередь, эмоциональное воздействие во французском интернет дискурсе выражается с помощью эмоционально окрашенной лексики. В эту категорию входят как лексические единицы, непосредственно называющие эмоции joie - радость, peur - страх, так и эмоционально окрашенные слова rire - смеяться, sourire - улыбаться. Интенсификации выражения эмоционального отношения служат прилагательные с сильной эмоциональной окраской infernal - адский, fabuleux невероятный, фантастический; превосходные степени прилагательных le plus beau - 
самый красивый; повтор наречия beauсоир - очень; метафорические выражения travail d'orfèvre - ювелирная работа.

В интернет-дискурсе эмоциональная лексика представлена также в виде хештегов, дающих эксплицитную интерпретативную информацию, в том числе связанную с выражением эмоций и модальностью сообщения. Эмоциональную окраску сообщению придают такие хештеги, как \#colère - гнев, \#joie - paдость, \#peur страх, \#ironie - ирония и т.п.

Выражение эмоционального отношения может осуществляться не только с помощью эмоциональной лексики. Интенсивность эмоций также отражает и использование междометий. Одни междометия могут служить для выражения как положительного, так и отрицательного эмоционального отношения, как например, $A h$ !, Oh! Другие ассоциируются с какой-то одной полярностью эмоции, как например, Beurk (выражение отвращения), Bof (выражение скуки, безразличия). Отсутствие междометий не меняет смысл сообщения, но снижает эмоциональную интенсивность сообщения и затрудняют определение отношения участников коммуникации к теме сообщения. Междометия часто сочетаются с лексическими единицами, выражающими сильные положительные или отрицательные эмоции, чтобы подчеркнуть интенсивность выражаемого эмоционального отношения: Ahhh! Super! Интенсивность эмоции может быть подчеркнута с помощью таких графических средств, как увеличение количества восклицательных знаков и повторение букв, имитирующее протягивание звуков: AAAh!! Aiiiiiiiiie!

В рамках интернет-дискурса особе место в плане силы эмоционального воздействия занимает язык вражды (хейтспич, риторика ненависти). Целью языка вражды является оскорбление, обесчеловечивание, запугивание, унижение представителей определенной группы и подстрекание к насилию в их отношении (Siapera, 2019). Исследование дискурса анти-мигрантской группы в Facebook «Sauvons Calais» («Спасем Кале») (Monnier, Seoane \& Gardenier, 2020) показало, что для него характерно использование военной метафоры, которая проявлялась в использовании таких лексических единиц, как attaque - наступление, défense оборона, ville assiégée - осажденный город и антитетических высказываний Ils ne fuient pas la guerre, ils viennent la faire chez nous - Они не бегут от войны, они пришли, чтобы вести ее у нас. Расхождение между выраженным напрямую и смыслом, скрытым говорящим помогает использование саркастических замечаний. Кроме этого в сообщениях сетевого сообщества «Sauvons Calais» прослеживается динамика стремления объединиться в группу между «своими», что проявляется в более частом употреблении местоимения «мы» по сравнению с местоимением «я». 
Исследование показало, что в хейтспиче можно выделить два уровня интенсивности: первый уровень - это оскорбительные сообщения, унижающие честь и достоинство, обесчеловечивающие оскорбления в виде сравнения людей с животными. Второй уровень интенсивности представляют собой агрессивные высказывания, побуждающие к действиям с глаголами в императивной форме и будущем времени.

\section{Выводы Conclusions}

Отражение эмоционального состояния человека в письменной речи отличается разной степенью достоверности, но в рамках непринужденной коммуникации в социальных сетях это возможно сделать максимально корректно в силу того, что для интернет-коммуникации характерна спонтанность, так как участники коммуникации стремятся максимально быстро обозначить свою позицию по той или иной теме. Выражение эмоционального отношения с помощью дискурсивных средств в рамках общения в социальных сетях осуществляется главным образом с помощью использования эмоциональной лексики, сила воздействия которой может усиливаться с помощью различных графических средств. Эмоциональное воздействие языка вражды обусловлено использованием как лексических, так и риторических дискурсивных средств.

\section{Литература} References

Баранов, А.Н. (2007). Лингвистическая экспертиза текста: теория и практика. Москва: Флинта.

Гребенщикова, Т.А., Кубрак, Т.А., \& Павлова, Н.Д. (2020). Дискурсивная реальность интернета. Вестник Московского государственного областного университета. Серия: Психологические науки, 1, 92-100.

Павлова Н.Д., Гребенщикова, Т.А., \& Кубрак, Т.А. (2020). Новая дискурсивная реальность: дискурсивный подход к изучению психологических процессов в интернет-среде. Н.В. Борисова, М.И. Воловикова, \& А.Л. Журавлев (Ред.), Индивидуальное, национальное и глобальное в сознании современного человека: новые идеи, проблемы, научные направления. Серия "Интеграчия академической и университетской психологии” (с. 697-705). Москва: Институт психологии РАН. 
Павлова, Н.Д. (2013). Механизмы и средства психологического воздействия в дискурсе. Психологические б(32). http://psystudy.ru/index.php/num/2013v6n32/905-pavlova32.html

Elouni, N. (2018). Etude de quelques formes d'expression des émotions et des sentiments dans le context des nouvelles formes de communication. (Thèse en sciences du langage). Dijon.

Monnier, A., Seoane, A., \& Gardenier, (2020). Analyser le discours de haine en ligne: réflexions méthodologiques In P. Vergely \& G. Carbou (Eds.), Médias et émotions. Catégories d'analyse, problématiques, concepts. Rome: RomaTrePress. https://doi.org/10.13134/979-12-80060-71-6

Siapera, E. (2019) Organised and Ambient Digital Racism: Multidirectional Flows in the Irish Digital Sphere. Open Library of Humanities, 5(1). https://doi.org/10.16995/olh.405 